\title{
Problem-based learning in public health workforce training: a discussion of educational principles and evidence
}

\author{
Lyndal J. Trevena \\ School of Public Health, The University of Sydney. \\ Email:lyndalt@health.usyd.edu.au
}

\begin{abstract}
Problem-based learning (PBL) has been implemented within numerous undergraduate health curricula but less so in workforce training. Public health practice requires many of the skills that PBL aims to develop such as teamwork, selfdirected learning and the integration of multiple sources of information within problem solving. This paper summarises the historical development of PBL and the educational principles underpinning it. It hypothesises that the public health workforce would benefit from some exposure to this type of learning and highlights some of the practical issues for its implementation.
\end{abstract}

Problem-based learning (PBL) was originally developed by Barrows and Tamblyn at McMaster University, Canada, to help medical students integrate knowledge across subject boundaries and develop problem-solving skills during their neurology training. ${ }^{1}$ PBL was educationally innovative because it allowed students to blend new knowledge acquired from external sources with their existing knowledge-base, and apply it. This paper provides a targeted review of the literature and a discussion of the development and use of PBL in health education. It raises questions about the potential application of PBL in public health workforce training.

\section{Defining PBL}

Other educational methods that bear a superficial resemblance to PBL, such as 'discovery learning', rely on students sharing their knowledge with each other but not obtaining it from external sources. PBL also differs from a 'case study approach', which tends to get students to solve problems after gaining some knowledge. Despite its rapid adoption over the last decade, particularly within medical curricula, there is still some confusion over what PBL means. $^{2}$
The distinguishing feature of PBL is that it begins with a problem and is followed by a student-centred enquiry process. There are no specific readings or lectures before students are presented with the problem. However, students bring previously acquired knowledge from a range of sources to what is usually a group of approximately eight randomly assigned learners and a tutor-facilitator. Students work collaboratively to define the problem, formulate enquiry plans and identify external sources for solving the problem. They also work together to analyse information and apply it. In medical education the problem often has a simulated or virtual patient, and uses a video or sometimes computer images of patient signs, symptoms, pathology and radiology results to mimic professional practice. The PBL process usually occurs over several tutorials within a week, allowing time for information to be gathered from external sources and brought back to the group process.

\section{Educational principles underpinning PBL}

Barrows defined four broad goals for PBL: ${ }^{3}$

(1) Motivational learning

(2) Developing effective clinical reasoning

(3) Developing self-learning skills

(4) Structuring knowledge in clinical contexts.

These goals were subsequently expanded by Schmidt, ${ }^{4}$ who defined seven steps to the PBL process (Box 1). Many variations to, and newer versions of, PBL have been developed since Barrows' work in the 1970s and Schmidt's in the 1980s, but most educators would probably agree that the principles above are the foundation on which PBL is built.

Box 1. Seven steps in problem-based learning.

1. Clarify terms and concepts not readily comprehensible

2. Define the problem

3. Analyse the problem

4. Draw a systematic inventory of the explanation inferred from step 3

5. Formulate learning objectives

6. Collect additional information outside the group

7. Synthesise and test the newly acquired information

Source: Schmidt H. Problem-based learning: Problem and definition. Medical Education 1983. ${ }^{4}$ 


\section{Matching educational methods with learning needs}

Many believe that PBL incorporates the principles of adult learning better than other modalities by encouraging the development of skills that prepare students for selfdirected life-long learning rather than the recall of facts that quickly go out-of-date. ${ }^{2,5}$ The PBL process therefore requires some cognitive skills of a high order.

Almost 50 years ago, Benjamin Bloom proposed a taxonomy of educational goals, with two domains, 'affective' and 'cognitive', comprising educational objectives of increasing complexity. ${ }^{6}$ In the affective domain, learning moves from receiving (e.g. attendance) through responding, valuing, organisation and finally characterisation. Thus, the affective domain becomes increasingly integrated within the learners' behaviour. In the cognitive domain, goals are achieved in both knowledge and skills. Knowledge attainment begins with facts and terminology, and considers trends, sequences, classifications, methodologies and finally principles and theories. Knowledge is then applied as an intellectual ability or skill via comprehension (i.e. translation, interpretation and extrapolation), application, analysis (of elements, of relationships and of organisational principles), synthesis (through unique communication, production of a plan or proposed set of operations, and derivation of abstract relations) and evaluation (judgements in terms of internal evidence and of external criteria). Clearly, PBL aims to achieve educational goals at both the high end of the affective domain and in knowledge and skills acquisition.

While the use of the word 'problem' implies that something needs 'fixing', within the learning context it can involve students being presented with a set of unfamiliar circumstances. In a PBL task, the students would be required not only to recognise patterns within the problem but also to obtain and apply knowledge in a logical and analytical way to solve the problem. ${ }^{7}$
Implementing the PBL method within a curriculum In addition to confusion about the nomenclature of PBL, there is confusion about its implementation within curricula. The PBL label has, according to some, been subverted and used in problem-oriented curricula. ${ }^{8}$ Ross maintains that the distinguishing characteristic of PBL is that knowledge arises from working on the problem rather than being a prerequisite for working on the problem. ${ }^{8}$ This is often an iterative process and usually self-directed, where learning occurs without the constraints of subject boundaries.

At what point then should students be exposed to PBL? Are they able to utilise this framework early in their learning or do they need to work towards it in some way? PBL has been used within undergraduate, graduate and continuing education environments but it is unclear whether it is equally effective at all three stages of learning. Barrows himself suggested that medical students might need to work towards PBL through a taxonomy of learning methods (Box 2). Only the final two truly provide a framework for achieving Barrows' four goals of PBL. Some PBL curricula use only these final two learning formats, while others allow students to work towards these by using case-based methods in the earlier part of their course. The most effective approach remains unclear.

\section{Evidence for the effectiveness of PBL}

The effectiveness of PBL as a learning method has been the source of much debate in the literature. 5,9 Three systematic reviews ${ }^{10-12}$ were conducted in the early 1990 s comparing PBL with traditional medical curricula, and these found some evidence (from students' opinions and attitudes to programs) that PBL graduates had a more positive learning experience, performed at least as well in clinical examinations and were more likely to enter family medicine than other graduates. There was also some evidence that basic science scores were lower in PBL graduates than in their traditionally taught counterparts. These systematic reviews were updated by Colliver in $2000,{ }^{9}$

Box 2. Barrows' taxonomy of problem-based learning.

- Lecture-based cases: cases used to demonstrate the relevance of information provided by lecture

- Case-based lectures: cases are used to highlight material to be covered in the subsequent lecture

- Case method: cases are studied in preparation for class discussion

- Modified case-based method: cases provide opportunities for deciding between a limited number of options

- Problem-based learning: cases are used in a problem simulation format encouraging free inquiry

- Closed loop, or reiterative, problem-based learning: a reflective phase complements the problem-based format

Source: Barrows $\mathrm{H}$. A taxonomy of problem-based learning methods. Medical Education 1986. ${ }^{3}$ 
who claimed that improvements in knowledge and clinical performance attributable to PBL were not great enough to be practically significant. This has been refuted by Blake et al., who published an analysis of United States Medical Licensing Examination results of four PBL classes compared with two traditional classes graduating from University of Missouri-Columbia School of Medicine. ${ }^{13}$ They showed that students from the PBL curricula had higher mean scores in the Step 1 examination (basic sciences) than those in the traditional curriculum. The PBL students also had scores higher than the national mean in the Step 2 examination (clinical sciences), unlike students in the traditional curriculum whose mean score was lower than the national mean. Both groups had similar selection characteristics and processes and Blake infers that the PBL learning process substantially contributed to this improved educational outcome.

Dean et al. ${ }^{14}$ compared the performance of NSW hospital interns who completed graduate entry PBL courses with that of interns who completed undergraduate PBL and traditional undergraduate courses in 2003. The analysis showed that graduate entry PBL interns felt more prepared in five of the eight assessed domains (interpersonal skills, confidence, collaboration, holistic care and self-directed learning) and felt no less prepared in any domain than the interns from the other courses. ${ }^{14}$

A systematic review of controlled evaluation studies in problem-based continuing medical education found limited evidence that it increased participants' knowledge and performance and improved patients' health. There was moderate evidence that doctors were more satisfied with PBL compared with traditional teaching approaches. ${ }^{15}$ Similar results have also been found in the evaluation of PBL methods within nursing, dentistry, pharmacy, anatomy, pharmacology and allied health curricula. ${ }^{16-20}$

In summary, there is evidence from medical and other health undergraduate curricula, as well as continuing medical education, that PBL graduates achieve equivalent, if not better, scores in knowledge-based assessments (mainly multiple choice question and short answer) and clinical examinations than their traditional counterparts. In addition to this, PBL curricula generally receive a higher satisfaction rating from students.

\section{Limitations of the evidence}

Revisiting Barrows' goals, PBL should produce graduates who are motivated, self-directed learners, who are able to develop effective reasoning strategies and structure knowledge effectively within the context to which it is applied. However, multiple choice questions, short answer questions, clinical examinations and satisfaction measures fall short of assessing whether these goals are achieved. The higher up Bloom's taxonomy one goes, the more dif- ficult it is to assess the educational outcomes. It is likely that workplace assessments, performance and evaluations across a range of outcomes are more appropriate. These could assess attitudes and skills as well as knowledge, thereby considering whether values such as interdisciplinary teamwork and skills in self-directed problem solving have been attained. There is a need for more research in this area.

A related issue to outcome measurement is the lack of available data on the cost-effectiveness of PBL curricula. This remains a substantive issue, as PBL is potentially resource-intensive, requiring skilled tutor-facilitators, high quality learning resources for self-directed problem solving and greater timetable allocation for small group work and associated facilities.

\section{PBL in public health education}

Public health practice involves considerable problem solving. It usually involves working within groups and with numerous stakeholders. And according to Bloom's taxonomy, it requires analytical and organisational skills of the highest order. The public health workforce comprises mainly tertiary-trained adult learners who are required to be self-directed and highly motivated in their work. They need to be able to obtain and synthesise information from external sources and to apply this to the problems, projects or circumstances before them.

Yet, the use of PBL in public health is largely uncharted territory. Several examples of case-based but not problembased learning in public health undergraduate and postgraduate courses exist, but they have not been formally evaluated, particularly in workforce training contexts. ${ }^{21-23}$ Some reports also exist on the integration of public health learning objectives within problem-based medical undergraduate curricula, but not on the use of this educational method to solve problems at a population level. ${ }^{24,25}$ The one exception to this is an innovative series of PBLs developed in Hong Kong, covering such topics as air pollution, tobacco control and mammography screening. ${ }^{26}$

What would one hope to achieve through problem-based public health workforce training? Would it result in higher levels of motivation, greater application of knowledge in the workplace, better teamwork and a more self-directed workforce? The NSW Public Health Officer Training Program may be one place to begin testing these ideas because it provides a structured and stable learning environment for a small number of trainees. There would be considerable educational challenges in developing a PBL approach to population rather than individual patient problem solving. Public health problems often have more than one solution; they are often extremely complex and may need to be broken down into several problems within a 'meta-problem'. As discussed earlier, there are also 
ongoing challenges in the assessment of competence in PBL learning outcomes that would need to be defined specifically for the public health context. Regardless of the clinical derivation of PBL, its educational principles nevertheless resonate with public health problem solving in practice.

\section{Implementing PBL in public health education}

The geographical dispersion of the public health workforce and competing workplace demands add a layer of complexity that does not exist for campus or hospitalbased medical undergraduate curricula. Most PBL curricula are conducted through small groups that remain stable for several problems, allowing for the development of team-working skills. When considering how PBL might be implemented in public health workforce training, it is important to consider public health team composition.

The delivery of PBL methods by distance learning is an emerging area. ${ }^{27,28}$ Teleconferencing and videoconferencing have been used with undergraduate nurses and in continuing medical education. While these modalities improve access to remote learners, there are numerous factors that can reduce the quality of learning. Limited reports on teleconferencing show a high time-demand on tutor-facilitators and difficulties in group facilitation due to a lack of visual cues. ${ }^{29}$ Although videoconferencing provides the visual dimension, it is costly and still requires a particular etiquette and considerable skill to ensure participation across several sites. ${ }^{30}$ Others have tried webbased asynchronous discussions within small online groups. While this method lacks the spontaneity of 'live' discussion, it has the benefit that people can participate at a time that suits their own working environment and other commitments. Responses can also be more reflective. ${ }^{31,32}$

Despite these challenges, the potential exists for substantial educational gains in a field that is, as yet, largely unexplored. In theory, the fundamental educational principles of PBL should be relevant to the learning needs of the NSW public health workforce. Translating the PBL framework to population level problem solving, defining the outcomes of the PBL process, measuring them and determining the most appropriate method of delivery will be crucial to the success of such a project. Pilot testing of this learning method within the NSW Public Health Officer Training Program and subsequent testing with more experienced NSW public health practitioners undertaking continuing education might begin to provide some answers to these questions.

\section{Acknowledgement}

This paper was commissioned by the NSW Department of Health.

\section{References}

1. Neufeld V, Barrows H. 'The McMaster philosophy': an approach to medical education. J Med Educ 1974; 49(11): 1040-50.

2. Maudsley G. Do we all mean the same thing by 'problembased learning'? A review of the concepts and a formulation of the ground rules. Acad Med 1999; 74(2): 178-85.

3. Barrows H. A taxonomy of problem-based learning methods. Med Educ 1986; 20: 481-6.

4. Schmidt H. Problem-based learning: problem and definition. Med Educ 1983; 17: 11-6.

5. Albanese M. Problem-based learning: why curricula are likely to show little effect on knowledge and clinical skills. Med Educ 2000; 34: 729-38. doi:10.1046/j.13652923.2000.00753.x

6. Bloom B, editor. Taxonomy of educational objectives: the classification of educational goals, by a committee of college and university examiners. Handbook I, Cognitive domain. New York: David McKay, 1956.

7. Walton H, Matthews M. Essentials of problem-based learning. Med Educ 1989; 23: 542-58.

8. Ross B. Towards a framework for problem-based curricula. In: Boud D, Feletti G, editors. The challenge of problem-based learning. London: Kogan Page, 1991.

9. Colliver J. Effectiveness of problem-based learning curricula: research and theory. Acad Med 2000; 75(3): 259-66. doi:10.1097/00001888-200003000-00017

10. Albanese M, Mitchell S. Problem-based learning: a review of literature on its outcomes and implementation issues. Acad Med 1993; 68: 52-81. doi:10.1097/00001888-19930100000012

11. Vernon D, Blake R. Does problem-based learning work? A meta-analysis of evaluative research. Acad Med 1993; 68: 550-63. doi:10.1097/00001888-199307000-00015

12. Berkson L. Problem-based learning: have the expectations been met? Acad Med 1993; 68(Suppl.): S79-88. doi:10.1097/00001888-199310000-00053

13. Blake R, Hosakowa M, Riley S. Student performances on Step 1 and Step 2 of the United States Medical Licensing Examination following implementation of a problem-based learning curriculum. Acad Med 2000; 75(1): 66-70. doi:10.1097/00001888-200001000-00017

14. Dean S, Barratt A, Hendry G, Lyon P. Preparedness for hospital practice among graduates of a problem-based, graduate-entry medical program. Med J Aust 2003; 178(4): $147-8$.

15. Smits P, Verbeek J, de Buisonje C. Problem-based learning in continuing medical education: a review of controlled evaluation studies. BMJ 2002; 324: 153-6. doi:10.1136/bmj.324.7330.153

16. Reynolds F. Initial experiences of interprofessional problembased learning: a comparison of male and female students' views. J Interprof Care 2003; 17(1): 35-44. doi:10.1080/1356182021000044148

17. Prince K, van Mameron H, Hylkema N, Drukker J, Shcherpbier A, van der Vleutin C. Does problem-based learning lead to deficiencies in basic science knowledge? An empirical case on anatomy. Med Educ 2003; 37: 15-21. doi:10.1046/j.1365-2923.2003.01402.x 
18. Pang S, Wong T, Dorcas A, Lai C, Lee R, Lee W et al. Evaluating the use of developmental action inquiry in constructing a problem-based learning curriculum for preregistration nursing education in Hong Kong: A student perspective. $J A d v$ Nurs 2002; 40(2): 230-41. doi:10.1046/j.1365-2648.2002.02365.x

19. International Problem-Based Learning Network Use of problem-based learning in Canadian and US dental schools: results of a survey. J Can Dent Assoc 2002; 68(1): 26.

20. Antepohl W, Herzig S. Problem-based learning versus lecturebased learning in a course of basic pharmacology: a controlled, randomized study. Med Educ 1999; 33(2): 106-13. doi:10.1046/j.1365-2923.1999.00289.x

21. Pearson T, Barker W, Fisher S, Trafton S. Integration of the case-based series in population-oriented prevention into a problem-based medical curriculum. Am J Prev Med 2003; 24(4): 102-7. doi:10.1016/S0749-3797(03)00030-8

22. Wiers R, van der Wiel M, Sa H, Mamede S, Tomaz J, Schmidt H. Design of a problem-based curriculum: a general approach and a case study in the domain of public health. Med Teach 2002; 24(1): 45-51. doi:10.1080/00034980120103478

23. Petersen D, Ginter P, Hovinga M, Williams O, Jacobs R, Davies S. Public health case studies: a new MPH requirement bridging academia and practice. $J$ Public Health Manag Pract 2001; 7(3): 86-91.

24. Trevena L, Clarke R. Self-directed learning in population health. A clinically relevant approach for medical students. Am J Prev Med 2002; 22(1): 59-65. doi:10.1016/S07493797(01)00395-6
25. Stone D. Public health in the undergraduate medical curriculum - can we achieve integration? J Eval Clin Pract 2000; 6(1): 9-14. doi:10.1046/j.1365-2753.2000.00227.x

26. Leung G, Lam T, Hedley A. Reports of new ideas in medical education: problem-based public health learning - from the classroom to the community. Med Educ 2001; 35: 1066-90. doi:10.1046/j.1365-2923.2001.1077a.x

27. Price B. Problem-based learning the distance learning way: a bridge too far? Nurse Educ Today 2000; 20: 98-105. doi:10.1054/nedt.1999.0379

28. Edwards N, Hugo K, Cragg B, Peterson J. The integration of problem-based learning strategies in distance education. Nurse Educ 1999; 24(1): 36-41. doi:10.1097/00006223-19990100000011

29. Choi H. A problem-based learning trial on the Internet involving undergraduate nursing students. J Nurs Educ 2003; 42(8): 359-63.

30. Allen M, Sargeant J, Mann K, Fleming M, Premi J. Videoconferencing for practice-based small-group continuing medical education: feasibility, acceptability, effectiveness and cost. J Contin Educ Health Prof 2003; 23(1): 38-47. doi:10.1002/chp.1340230107

31. Salmon G. E-moderating: the key to teaching and learning online. London: Kogan Page, 2000.

32. Elwyn G, Greenhalgh T, MacFarlane F. Groups: a guide to small group work in healthcare, education and research. Oxford: Radcliffe Medical Press, 2001.

\section{Bug Breakfast Delivery Manual available on the NSW Health Intranet}

The Bug Breakfast Delivery Manual has been developed as a resource to assist the delivery of professional development activities by videoconference.

The Public Health Training and Development Branch and Communicable Diseases Branch of the NSW Department of Health coordinate the delivery of Bug Breakfast (a series of hour-long breakfast seminars on communicable diseases that are held monthly). The seminars are delivered to an on-site audience at the Department of Health in North Sydney and are broadcast via videoconference to 19 remote sites across NSW.

To support the regular delivery of Bug Breakfast, the Public Health Training and Development Branch has developed a Bug Breakfast Delivery Manual. The Manual provides a complete description of the procedures to be followed and resources required to deliver a live training session to multiple remote sites via videoconference.

Other groups that use videoconferencing to deliver professional development activities may find the Manual a useful resource. The Manual will be updated annually and is available to be downloaded from the Bug Breakfast web pages on the NSW Health Intranet site.

The Bug Breakfast web pages can be accessed from the NSW Health Intranet site at the following web address: http://internal.health.nsw.gov.au/public-health/bugbreakfast/index.html.

For further information about Bug Breakfast or the Bug Breakfast Delivery Manual, contact the Bug Breakfast Coordinator, Public Health Training and Development Branch, NSW Department of Health by email at BugBreakfast@doh.health.nsw.gov.au. 